\title{
Quality Indicators for Evaluating Errors in the Preanalytical Phase
}

\author{
Mohit Mehndiratta ${ }^{1}$ Eram Hussain Pasha ${ }^{1}$ Nilesh Chandra ${ }^{2} \quad$ Edelbert Anthonio Almeida ${ }^{1}$ \\ ${ }^{1}$ Department of Biochemistry, University College of Medical \\ Sciences and Guru Teg Bahadur Hospital, New Delhi, India \\ ${ }^{2}$ Clinical Biochemistry, Clinical Diagnostic Centre, Delhi, India

\begin{abstract}
Address for correspondence Nilesh Chandra, MD, Clinical Biochemistry, Clinical Diagnostic Centre, 69, Hargovind Enclave, Karkardooma, Delhi 110092, India (e-mail: drnileshchandra@gmail.com).
\end{abstract}

J Lab Physicians 2021;13:169-174.

\begin{abstract}
Keywords

- quality indicators

- preanalytical phase

- laboratory errors

- patient care

Objective The aim of this study was to study the incidence of preanalytical errors in the clinical chemistry laboratory attached to a tertiary care hospital.

Design and Methods The study was conducted in a clinical chemistry laboratory using the samples and forms received for analysis. Five hundred random samples were analyzed using a predefined set of quality indicators (QIs) over a period of 3 months. The incidence of each preanalytical error was described as a percentage of the total samples analyzed in the study.

Statistical Analysis Individual QIs were assigned values as 0 and 1 and were used to assess each sample; 0 if the error was present, and 1 if absent. The incidence of each preanalytical error was described as a percentage of the total samples analyzed in the study.

Result Out of the 500 samples observed, 138 samples were error free, while 21 samples had the maximum number of errors, that is, 6 . The error committed most often was the omission of provisional diagnosis being mentioned on the requisition form. No preanalytical error was observed for Qls: selecting the appropriate blood collection vial or storage of sample.

Conclusion This study confirms that error rate in the preanalytical phase is high and vastly ignored. Errors committed here may be overlooked, given the large number of samples received in the clinical laboratory of a tertiary center. To reduce these errors, the laboratory should provide training to all workers involved in the preanalytical phase. Daily or weekly QI scores should be recorded to assess and rectify shortcomings, thereby improving patient care.
\end{abstract}

\section{Introduction}

Medical error has been listed as the third leading cause of death in the United States as per a study done by researchers at the John Hopkins University School of Medicine. ${ }^{1}$ Laboratory errors also contribute to medical error as the management of a patient is often interwoven with their bloodwork. Advancements in science and technology have helped us

published online May 26, 2021
DOI https://doi.org/ 10.1055/s-0041-1729473 ISSN 0974-2727 significantly reduce, if not eliminate, the errors occurring in the analytical and postanalytical stages of the total testing cycle, owing to development in automation and the technologies pertaining to it. However, the preanalytical stage that is mostly dependent on manual labor still has a far way to go. ${ }^{2}$

The total testing process (TTP) (or the total testing cycle) in the clinical laboratory is based on the original brain-to-brain loop concept ${ }^{3}$ that outlined a series of activities, starting

C 2021. The Indian Association of Laboratory Physicians.

This is an open access article published by Thieme under the terms of the Creative Commons Attribution-NonDerivative-NonCommercial-License, permitting copying and reproduction so long as the original work is given appropriate credit. Contents may not be used for commercial purposes, or adapted, remixed, transformed or built upon. (https://creativecommons.org/licenses/by-nc-nd/4.0/).

Thieme Medical and Scientific Publishers Pvt. Ltd. A-12, 2nd Floor, Sector 2, Noida-201301 UP, India 
with the clinical question in the clinician's mind, leading to test selection, sample collection, transport to the laboratory, analysis, reporting back to the clinician, and the final interpretation and decision making by the clinician. All these activities have traditionally been separated into three phases: preanalytical, analytical, and postanalytical. The TTP must be managed properly during all the phases by a laboratory for deliverance of accurate and reliable results.

The preanalytical phase encompasses all the processes from the time of a laboratory request made by the physician until the specimen is analyzed in the laboratory (e.g., patient preparation, blood drawing, sample transportation, centrifugation, and dilutions). The analytical stage involves the analysis of the analytes using automation, especially in clinical biochemistry laboratory, and the validation of test results. The postanalytical stage refers to the interpretation of results by laboratory consultants and reporting the same to the clinicians via printed reports. ${ }^{4}$ Laboratory errors might occur at any of these three phases, but the preanalytical phase is reported to be most prone to inadvertent introduction of errors. ${ }^{5}$ Various studies have reported that 46 to $68 \%$ of laboratory errors occur in the preanalytical phase, whichcontributes to a great extent to the overall burden of medical errors. ${ }^{6,7}$ Majority of the steps in preanalytical phase like test requesting, patient and sample identification, blood collection, sample handling, and transportation usually are not performed in the clinical laboratory and, therefore, are monitored unsatisfactorily. ${ }^{8}$

The Institute of Medicine (IOM) (Washington DC, United States) has defined quality indicators (QIs), which is a crucial step in enabling users to quantify the quality of a selected aspect of care by comparing it against a defined criterion. ${ }^{9} \mathrm{~A}$ QI is thus "an objective measure that potentially evaluates all critical care domains as defined by the IOM (patient safety, effectiveness, equity, patient-centeredness, timeliness and efficiency), that is based on evidence associated with those domains, and can be implemented in a consistent and comparable manner across settings and over time." ${ }^{10}$ Therefore, when assessing the quality of laboratory services using QIs, it is important to ensure systematic and consistent data collection and analysis by using a comprehensive set of indicators that address all stages of the TTP and focus on the areas that have an important impact on patient care and their health outcomes.

The development of QIs is a fundamental step in providing sound evidence of quality in all procedures and processes of the TTP. ${ }^{5}$ Keeping in view the necessity of monitoring QIs, this study was designed to study the incidence of preanalytical errors in the clinical chemistry laboratory of a tertiary care hospital. This is the first step to check the preanalytical errors in a structured format that will help us in improving patient care.

\section{Materials and Methods}

A descriptive study on preanalytical errors in a clinical biochemistry laboratory was conducted at the Department of Biochemistry of our institute. Simple random sampling was done for a total of 500 ( 418 chemistry and 82 hematological) samples whereeach samplewas chosen and assessed randomly and entirely by chance, such that each individual sample would have the same probability of being chosen at any stage during the sampling process. Ethylenediaminetetraacetic acid, sodium fluoride, and plain vials (with clot activator) were observed. Random sampling was done over a period of 3 months and ethical clearance was obtained from the Institutional Ethics Committee of our college. During this study period, each individual sample was assessed as per the predefined QIs. Accordingly, the test requisition forms as well as the individual vials were carefully examined. Samples were inspected, centrifuged, and forwarded for individual analysis. No interaction was held with the patients at any stage of the study, and full confidentiality of all records assessed was maintained. The QIs observed ${ }^{11}$ are mentioned in - Table 1. Individual QIs were assigned the values of 0 and 1 , which were then used to assess each sample; 0 if the error was present, and 1 if absent (-Supplementary Table S1 [online only]). The maximum score that was assigned to the samples examined was 16 and the minimum was 0 , indicating the absence or presence of errors pertaining to the QIs. The incidence of each preanalytical error was described as a percentage of the total samples analyzed in the study.

Table 1 List of quality indicators (QI) in the preanalytical phase

\begin{tabular}{|l|l|}
\hline $\begin{array}{l}\text { QI-1: Appropriateness of } \\
\text { test request }\end{array}$ & $\begin{array}{l}\text { Number of requests with clinical } \\
\text { question (\%) }\end{array}$ \\
\hline $\begin{array}{l}\text { QI-2: Appropriateness of } \\
\text { test request }\end{array}$ & $\begin{array}{l}\text { Number of appropriate tests with } \\
\text { respect to the clinical question (\%) }\end{array}$ \\
\hline $\begin{array}{l}\text { QI-3: Examination } \\
\text { requisition }\end{array}$ & $\begin{array}{l}\text { Number of requests without } \\
\text { physician's identification (\%) }\end{array}$ \\
\hline $\begin{array}{l}\text { QI-4: Examination } \\
\text { requisition }\end{array}$ & $\begin{array}{l}\text { Number of unintelligible } \\
\text { requests (\%) }\end{array}$ \\
\hline QI-5: Identification & $\begin{array}{l}\text { Number of requests with } \\
\text { erroneous patient identification (\%) }\end{array}$ \\
\hline QI-6: Identification & $\begin{array}{l}\text { Number of requests with errone- } \\
\text { ous identification of physician (\%) }\end{array}$ \\
\hline QI-7: Test request & $\begin{array}{l}\text { Number of requests with errors } \\
\text { concerning test input (\%) }\end{array}$ \\
\hline QI-8: Samples & $\begin{array}{l}\text { Number of samples lost/not } \\
\text { received (\%) }\end{array}$ \\
\hline QI-9: Samples & $\begin{array}{l}\text { Number of samples collected in } \\
\text { inappropriate containers (\%) }\end{array}$ \\
\hline QI-10: Samples & $\begin{array}{l}\text { Number of samples hemolyzed } \\
\text { (hematology, chemistry) (\%) }\end{array}$ \\
\hline QI-11: Samples & $\begin{array}{l}\text { Number of samples clotted } \\
\text { (hematology, chemistry) (\%) }\end{array}$ \\
\hline QI-12: Samples & $\begin{array}{l}\text { Number of samples with } \\
\text { insufficient volumes (\%) }\end{array}$ \\
\hline QI-13: Samples & $\begin{array}{l}\text { Number of samples with } \\
\text { inadequate sample-anticoagulant } \\
\text { ratio (\%) }\end{array}$ \\
\hline QI-15: Samples & $\begin{array}{l}\text { Number of samples damaged in } \\
\text { transport (\%) }\end{array}$ \\
\hline $\begin{array}{l}\text { Number of improperly labeled } \\
\text { samples (\%) }\end{array}$ \\
$\begin{array}{l}\text { Number of improperly stored } \\
\text { samples (\%) }\end{array}$ \\
\hline Qumples
\end{tabular}




\section{Results}

Out of the 500 samples analyzed, only 138 samples (27.6\%) were found to be error free. In a single sample, the maximum errors recorded were 6 . Twenty-one such samples were encountered (4.2\%). Other QI scores obtained along with the number of samples scoring the same are mentioned in

\section{- Table 2.}

Individual QI analysis is given in - Fig. 1 and - Table 3.

Most errors (46.2\%) were committed while ordering the test, that is, appropriate tests with the clinical requisition being mentioned (QI-1), meaning whether the desired tests were mentioned with the provisional diagnosis. About 10.2\% of the sample slips had errors regarding the provisional diagnosis and the test being ordered (QI-2).

About $20.8 \%$ of the errors were related to requisition forms being submitted without the physician's identification (QI-3), that is, they were without the signature and stamp

Table 2 Overall quality indicator (QI) scores obtained

\begin{tabular}{|l|l|l|}
\hline QI score & $\begin{array}{l}\text { Number of samples } \\
(\boldsymbol{n}=\mathbf{5 0 0})\end{array}$ & Percentage \\
\hline 16 & 138 & $27.6 \%$ \\
\hline 15 & 26 & $5.2 \%$ \\
\hline 14 & 130 & $26 \%$ \\
\hline 13 & 81 & $16.2 \%$ \\
\hline 12 & 52 & $10.4 \%$ \\
\hline 11 & 52 & $10.4 \%$ \\
\hline 10 & 21 & $4.2 \%$ \\
\hline
\end{tabular}

Note: The table depicts the over QI scores obtained, expressed both as values and percentage. Each sample observed was scored 0 points in the presence of an error and 1 point in the absence of an error. A total of 16 Qls were observed. Thus, a QI score of 16 would indicate an error-free sample and a score of 0 would indicate the presence of all 16 errors. of the physician requesting the test. About $12.6 \%$ of the test requisition forms were illegible (QI-4). This was followed by requests with erroneous patient identification, that is, a mismatch between the name of the patient on the vial and on the requisition form, which accounting for $5.2 \%$ of the total preanalytical errors (QI-5).

There were no errors accountable to erroneous identification of the physician (QI-6), that is, mismatch between the name and stamp of the physician requesting the test.

About $1.5 \%$ of the errors accounted to either the requisition form or the vial missing from the laboratory (QI-8). There were no errors encountered due to samples being collected in wrong containers (QI-9). About $1.7 \%$ of the samples examined were hemolyzed, thereby indicating errors in sample collection (QI-10). While $0.5 \%$ of whole blood samples received were clotted, indicating inappropriate sample to anticoagulant ratio or delay in the transfer of sample from syringe to the vial. (QI-11). About $14.2 \%$ of the samples received at the laboratory contained insufficient volumes (QI-12), thereby having inadequate sample anticoagulant ratio (QI-13). About $0.0 .7 \%$ of the errors were because of damage done to the sample in transport (QI-14). About 3.5\% of the request forms had improperly labeled samples with the patient information being incomplete or absent (QI-15). There were no errors accounting to improper storage of samples (QI-16).

\section{Discussion}

The introduction of automation in the Clinical Chemistry Laboratory has resulted in a significant reduction in the rate of errors, particularly in the analytical and postanalytical phase; however, the same cannot be said about the preanalytical phase.

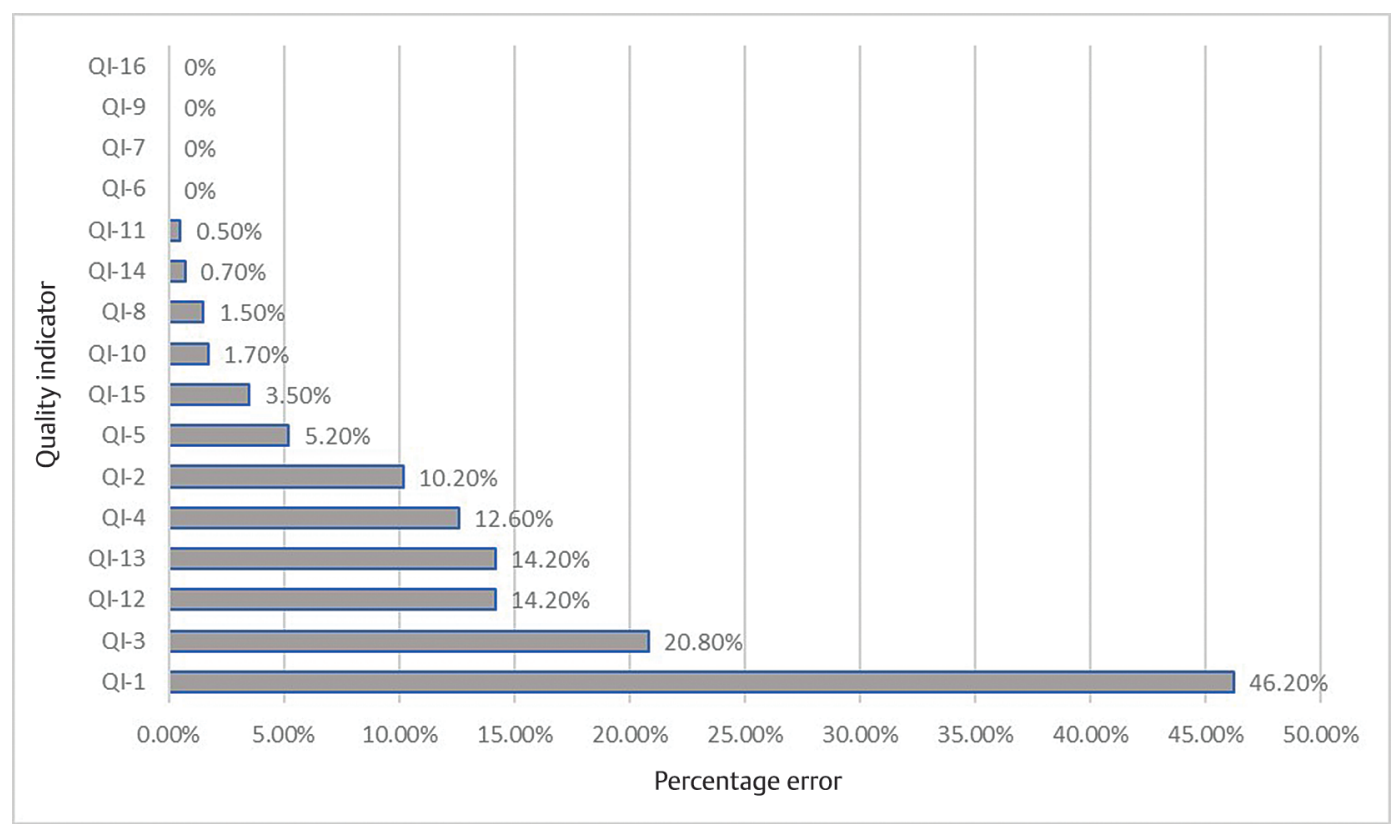

Fig. 1 Graph depicting individual quality indicator errors (\%) for the 500 samples observed. Number of samples observed to be having a particular error out of the 500 samples observed expressed as percentage ( $x$-axis) versus the respective quality indicator ( $y$-axis). 
Table 3 Individual quality indicator (QI) error (\%) for the 500 samples observed

\begin{tabular}{|c|c|c|}
\hline Quality Indicator & $\begin{array}{l}\text { Number of } \\
\text { erroneous } \\
\text { samples ( } n= \\
500 \text { ) }\end{array}$ & $\begin{array}{l}\text { Percentage } \\
\text { error }\end{array}$ \\
\hline $\begin{array}{l}\text { QI-1. Number of requests } \\
\text { with clinical question }\end{array}$ & 231 & $46.2 \%$ \\
\hline $\begin{array}{l}\text { QI-3. Number of requests } \\
\text { without physician's } \\
\text { identification }\end{array}$ & 104 & $20.8 \%$ \\
\hline $\begin{array}{l}\text { QI-12. Number of } \\
\text { samples with insufficient } \\
\text { volumes }\end{array}$ & 71 & $14.2 \%$ \\
\hline $\begin{array}{l}\text { QI-13. Number of } \\
\text { samples with inadequate } \\
\text { sample-anticoagulant } \\
\text { ratio }\end{array}$ & 71 & $14.2 \%$ \\
\hline $\begin{array}{l}\text { QI-4. Number of unintelli- } \\
\text { gible requests }\end{array}$ & 63 & $12.6 \%$ \\
\hline $\begin{array}{l}\text { QI-2. Number of appro- } \\
\text { priate tests with respect } \\
\text { to the clinical question }\end{array}$ & 51 & $10.2 \%$ \\
\hline $\begin{array}{l}\text { QI-5. Number of requests } \\
\text { with erroneous patient } \\
\text { identification }\end{array}$ & 21 & $5.2 \%$ \\
\hline $\begin{array}{l}\text { QI-15. Number of } \\
\text { improperly labeled } \\
\text { samples }\end{array}$ & 14 & $3.5 \%$ \\
\hline $\begin{array}{l}\text { QI-10. Number of sam- } \\
\text { ples hemolyzed (hema- } \\
\text { tology, chemistry) }\end{array}$ & 7 & $1.7 \%$ \\
\hline $\begin{array}{l}\text { QI-8. Number of samples } \\
\text { lost/not received }\end{array}$ & 6 & $1.5 \%$ \\
\hline $\begin{array}{l}\text { QI-14. Number of } \\
\text { samples damaged in } \\
\text { transport }\end{array}$ & 3 & $0.8 \%$ \\
\hline $\begin{array}{l}\text { QI-11. Number of sam- } \\
\text { ples clotted (hematology, } \\
\text { chemistry) }\end{array}$ & 2 & $0.5 \%$ \\
\hline $\begin{array}{l}\text { QI-6. Number of requests } \\
\text { with erroneous identifica- } \\
\text { tion of physician }\end{array}$ & 0 & $0 \%$ \\
\hline $\begin{array}{l}\text { QI-7. Number of requests } \\
\text { with errors concerning } \\
\text { test input }\end{array}$ & 0 & $0 \%$ \\
\hline $\begin{array}{l}\text { QI-9. Number of samples } \\
\text { collected in inappropriate } \\
\text { containers }\end{array}$ & 0 & $0 \%$ \\
\hline $\begin{array}{l}\text { QI-16. Number of } \\
\text { improperly stored } \\
\text { samples }\end{array}$ & 0 & $0 \%$ \\
\hline
\end{tabular}

Out of the 16 QIs assessed during this study, the maximum error (accounting to 46.2\%) was "tests ordered without clinical requisition/indication (QI-1)," which accounted for $46.2 \%$ of the errors, compared with a much lower $11.2 \%$ error rate in another study. ${ }^{12}$ The inclusion of provisional diagnosis of a patient on a requisition form helps the laboratory specialist to correlate the test report with the patient's diagnosis, thereby decreasing the tendency to order reruns for a particular analyte in view of the initially obtained abnormal values. It also prevents the laboratory specialist from unnecessarily rethinking the calibration of the autoanalyzer, thereby allowing timely delivery of reports and conservation of resources. The discrepancy in numbers in this study and the other study mentioned could be due to heavy work load, lack of standardization in filling test requests, as well as the lack of training of laboratory staff regarding the acceptance of these forms. Another possible reason is the minimal interaction between the clinician and the laboratory specialist regarding interpretation and the need for a patient's follow-up testing.

Errors were also noted in QI-3, that is, requisition slips without the physician's identification (20.8\%), which indicates a problem pertaining to the validity of the test being requisitioned. Another study reported this error rate to be $14.03 \%{ }^{13}$

A $14.2 \%$ error rate was noted for QI-12 and QI-13, that is, samples with insufficient volumes and an inadequate sample-anticoagulant ratio, respectively, which accounted to a comparable $12 \%$ in a different study. ${ }^{13}$ Another study reported $1.02 \%$ error rate for samples with insufficient volume. ${ }^{14} \mathrm{~A}$ possible explanation for these errors could be the inadequate training of the phlebotomist or their lack of experience, especially when it comes to pediatric patients, or the onset of fatigue, especially in government-run hospitals where the daily sampling is often on the higher side. ${ }^{14}$ Manufacturing defects or the use of poor-quality sampling material could also contribute to this error, along with poor rationing of the sample collected into different vials when a battery of tests is ordered.

Unintelligible request forms (QI-4) contributed to $12.6 \%$ of errors. This could be mainly attributed to excessive work load in government setups. For example, at our hospital, a minimum of 400 samplings of outpatients are done on a daily basis, not to mention the 20 out of 30 admitted patients that are sampled per ward, leading to indecipherable test requisition form filling. This could be rectified by a bar coding system with stickers for the sample vials or an electronic medical record system for the requisition of tests. We also analyzed $(n=10)$ samples randomly to see whether the errors observed were more in inpatient department (IPD) or outpatient department (OPD) samples. IPD sample collection was more erroneous than the OPD samples, where nurses and the paramedical staff usually collected samples, many of whom did not recognize/were not aware of the importance of the collection of samples by using the correct techniques. This may also be caused by rotational duties, excessive workload, and the variety of workload. ${ }^{15} \mathrm{~A}$ further study is planned in this regard.

A mismatch between a patient's name on the vial and on the requisition form, that is, erroneous patient identification (QI-5) accounted for 5.2\% of the errors, compared with an error rate of 27 and $0.26 \%$ in two other studies. ${ }^{13,14}$ Heavy workload and inexperience of the hospital staff contribute significantly to this error. If such samples are processed and reported, it could lead to misdiagnosis and mismanagement of a patient, which could have disastrous outcomes. ${ }^{14}$ Wristbands with 
individual barcodes as well as the compulsive need to match sample details to patient details prior to sample processing could be of great potential in reducing such errors.

Hemolysis is a documented cause of falsification in the value of analytes such as aldolase, total acid phosphatase, lactate dehydrogenase isocitrate dehydrogenase, potassium, magnesium, and phosphate. ${ }^{12}$ In this study, $1.7 \%$ of the samples received were hemolyzed (QI-10), while $0.5 \%$ of them had clotted (QI-11). Another study reported the percentage of hemolyzed and clotted samples as high as $26 \% .{ }^{16}$ Hemolysis mainly results due to inappropriate sampling techniques such as cleansing the venipuncture site with alcohol and not allowing the site to dry appropriately (at least 30 seconds), syringe draws, vigorous mixing of the samples, transferring the sample into a tube by pushing down on the syringe plunger to force blood into a tube, and not allowing the blood specimen to clot for the recommended amount of time. ${ }^{17}$ Clotting of blood mostly results from improper anticoagulant to blood ratio or delay in transferring blood from a syringe into the vial. Clotting leads to cell damage and consumption of coagulation factors, thereby rendering the sample useless for tests where plasma or whole blood is needed for testing. Both these errors are operator dependent and, therefore, proper training in phlebotomy goes a long way in preventing these errors.

Proper labeling of vials prior to sampling is of utmost importance because it is difficult to tracethe sample source after the sampling is done, and error at this stage could lead to falsification or swapping of reports, leading to confusion amongst the attending doctors and mismanagement of the patient. In this study, 3.5\% of the samples received were improperly labeled (QI-15), that is, there was a mismatch between the patient details on the vial and on the requisition form, or the vials were incompletely labeled.

Proper transportation of samples from the site of collection to the laboratory is also of utmost importance. In this study, $0.8 \%$ of samples were damaged during transit (QI-14), which could lead to loss of sample volume, mixing of samples, loss of sterility, and exposure of the public to infectious materials. About $1.5 \%$ of the samples could not be traced (QI-8), meaning the requisition form reached the laboratory but the sample did not. The possible explanation for this could be failure to dispatch the sample from the collection center, misplacement of the sample on the way to the laboratory, or mix up of requisition forms. This can all lead to confusion at the laboratory and the collection center, exposure of the public to infectious material, improper disposal of biomedical waste, and lastly the need of repeat sampling, which could be problematic particularly in pediatric and neonatal patients.

There were no errors accounting to requests with erroneous identification of the physician (QI-6), errors concerning test input (QI-7), samples collected in inappropriate containers (QI-9), or improperly stored samples (QI-16) in our study.

Most errors when identified lead to sample rejection at the laboratory prior to processing, thereby necessitating the need for resampling and increasing the workload of the hospital staff, wastage of hospital resources, adding to the patient's discomfort, and ultimately causing unnecessary delay in the reports.

The highest QI score as mentioned in - Table 2 that was encountered in our study was 16 , corresponding to 0 errors in 138 out of 500 samples (27.6\%), thereby indicating the poor standardization skills and dearth of training for medical laboratory personnel, as well as an immediate need for the identification and rectification of the problems owing to erroneous results. The lowest QI score observed was 10, indicating the presence of 6 errors in a single sample, accounting to $4.2 \%$ of the total samples.

The following implications can be drawn from this study: QI scores when maintained either on a daily or weekly basis can help improve the efficiency of the laboratory by highlighting the preanalytical areas that need to be focused upon, so that appropriate remedial measures can be taken. It can also be used as a parameter for assessment in laboratories pre- and postintervention. One should aim for a score of 16 in all samples.

There are a few limitations in our study: Small sample size, no adequate division of samples received from the wards (inpatient) and the blood collection centers (outpatient), no division of the samples received during the day shift and the night shift. A future study is planned in this regard, as stated earlier. This study also lacks interventions/workplace assessments post training, which would have been able to provide knowledge on what all areas of the preanalytical error spectrum can be rectified post intervention.

To conclude, there is an indispensable need to standardize laboratories in terms of the occurrence of errors in all phases: preanalytical, analytical, and postanalytical. As the available literature emphasizes the vulnerability of the preanalytical phase, the application and control of valuable QIs is an indispensable tool for identifying the most critical steps and reducing the risk of errors in the initial phase of the testing cycle itself. Furthermore, all laboratories running across a state or country should follow standard norms, run internal quality controls on a daily basis, and participate in external quality control programs. All the staff working in a laboratory should be given appropriate training and should participate regularly in continuing medical education programs. Greater integration of clinical and laboratory training programs, increased involvement of laboratory specialists with a medical background in the clinical laboratory to enhance clinician-laboratory interaction, and digitization/automation of as many steps as possible can be other possible interventions to improve laboratory performance, leading to better outcomes in patient management, which is the end goal of all medical centers.

\section{Author Contribution}

Mohit Mehndiratta was actively involved in designing the study as well as the acquisition, analysis, and interpretation of the data collected. He was involved in revising the content and has given the final approval for the same. Eram Hussain Pasha was involved in the acquisition, 
analysis, and interpretation of data. She was actively involved in drafting the content and has given her final approval. Nilesh Chandra was actively involved in the designing of the study and interpretation of the data. He was involved in revising the content and has given his final approval for the same. Almeida Edelbert Anthonio was involved in the analysis and interpretation of data. He was actively involved in drafting the content and has given his final approval. All authors have agreed to be held accountable for all aspects of the work in ensuring that questions related to the accuracy or integrity of any part of the work are appropriately investigated and resolved.

\section{Ethical Approval}

Approval of the Institutional Ethics Committee was obtained.

\section{Financial Aid and Sponsorship}

This research did not receive any specific grant from funding agencies in the public, commercial, or not-for-profit sectors.

\section{Conflict of Interest}

None declared.

\section{Acknowledgment}

None.

\section{References}

1 Makary MA, Daniel M. Medical error-the third leading cause of death in the US. BMJ 2016;353:i2139

2 Baron JM, Mermel CH, Lewandrwski KB, Dighe AS. Detection of preanalytical laboratory testing errors using statistically guided protocol. Am J Clin Pathol 2012;138(3):406-413

3 Lundberg GD. Acting on significant laboratory results. JAMA 1981;245(17):1762-1763
4 Cornes MP, Atherton J, Pourmahram G, et al. Monitoring and reporting of preanalytical errors in laboratory medicine: the UK situation. Ann Clin Biochem 2016;53(Pt 2) :279-284

5 Lippi G, Chance JJ, Church S, et al. Preanalytical quality improvement: from dream to reality. Clin Chem Lab Med 2011;49(7):1113-1126

6 Plebani M. Errors in clinical laboratories or errors in laboratory medicine? Clin Chem Lab Med 2006;44(6):750-759

7 Lippi G, Guidi GC, Mattiuzzi C, Plebani M. Preanalytical variability: the dark side of the moon in laboratory testing. Clin Chem Lab Med 2006;44(4):358-365

8 Laposata M, Dighe A. "Pre-pre" and "post-post" analytical error: high-incidence patient safety hazards involving the clinical laboratory. Clin Chem Lab Med 2007;45(6):712-719

9 Institute of Medicine Committee to Design a Strategy for Quality Review and Assurance in Medicare. Medicare: A Strategy for Quality Assurance. Washington, DC: National Academies Press; 1990

10 Institute of Medicine Committee on Quality of Health Care in America, To Err Is Human: Building a Safer Health System. Washington, DC: National Academies Press; 2000

11 Plebani M. Quality indicators to detect pre-analytical errors in laboratory testing. Clin Biochem Rev 2012;33(3):85-88

12 Bhavsar M, Javia H, Chinawale C, Bhimani N, Shah R. Pre-analytical errors in clinical chemistry laboratory of a tertiary care hospital. Int J Sci Res (Ahmedabad) 2018;7(4):27-29

13 Wiwanitkit V. Types and frequency of preanalytical mistakes in the first Thai ISO 9002:1994 certified clinical laboratory, a 6 - month monitoring. BMC Clin Pathol 2001;1(1):5

14 Sushma BJ, Shrikant C. Study on "Pre-analytical Errors in a Clinical Biochemistry Laboratory": The Hidden Flaws in Total Testing. Biochem Anal Biochem 2019;8:374

15 Chawla R, Goswami V, Tayal D, Mallika V. Identification of the types of preanalytical errors in the clinical chemistry laboratory: 1-year study of GB Pant Hospital. Lab Med 2010;41:89-92

16 Najat D. Prevalence of pre-analytical errors in clinical chemistry diagnostic labs in Sulaimani City of Iraqi Kurdistan. PLoS One 2017;12(1):e0170211

17 Calmarza P, Cordero J. Lipemia interferences in routine clinical biochemical tests. Biochem Med (Zagreb) 2011;21(2):160-166 